\title{
Luteolin sensitizes the antitumor effect of cisplatin in drug-resistant ovarian cancer via induction of apoptosis and inhibition of cell migration and invasion
}

\author{
Haixia Wang ${ }^{1 *+} \mathbb{D}$, Youjun $\mathrm{Luo}^{2+}$, Tiankui Qiao $^{2}$, Zhaoxia $\mathrm{Wu}^{3}$ and Zhonghua Huang ${ }^{1}$
}

\begin{abstract}
Luteolin, a polyphenolic flavone, has been demonstrated to exert anti-tumor activity in various cancer types. Cisplatin drug resistance is a major obstacle in the management of ovarian cancer. In the present study, we investigated the chemo-sensitizing effect of luteolin in both cisplatin-resistant ovarian cancer cell line and a mice xenotransplant model. In vitro, CCK-8 assay showed that luteolin inhibited cell proliferation in a dose-dependent manner, and luteolin enhanced anti-proliferation effect of cisplatin on cisplatin-resistant ovarian cancer CAOV3/DDP cells. Flow cytometry revealed that luteolin enhanced cell apoptosis in combination with cisplatin. Western blotting and GRT-PCR assay revealed that luteolin increased cisplatin-induced downregulation of BCl-2 expression. In addition, wound-healing assay and Matrigel invasion assay showed that luteolin and cisplatin synergistically inhibited migration and invasion of CAOV3/DDP cells. Moreover, in vivo, luteolin enhanced cisplatin-induced reduction of tumor growth as well as induction of apoptosis. We suggest that luteolin in combination with cisplatin could potentially be used as a new regimen for the treatment of ovarian cancer.
\end{abstract}

Keywords: Luteolin, Cisplatin-resistant ovarian cancer, Apoptosis, Migration, Invasion

\section{Introduction}

Ovarian cancer is one of the most common malignant tumors of gynecology, with the highest mortality compared with other gynecologic cancer because of its acute onset, rapid progress and high metastasis rate $[1,2]$. Epithelial ovarian cancer (EOC) accounts for $85-90 \%$ of total ovarian carcinoma and is the most aggressive one. In early stage, surgical resection combined with chemotherapy is an effective therapy method [3]. Unfortunately, most of the patients reach advanced stage at the time of diagnosis $[4,5]$. For patients with advanced EOC, platinum-based chemotherapy is the standard of care. More than $80 \%$ of ovarian tumors response to first-line platinum-based therapy [6], however, the majority of patients acquire resistance to cisplatin (CDDP)

\footnotetext{
* Correspondence: 18930819496@163.com

+Haixia Wang and Youjun Luo contributed equally to this work. 'Department of Obstetrics and Gynecology, Jinshan branch of Shanghai Sixth People's Hospital, Shanghai Jiaotong University, Shanghai, China Full list of author information is available at the end of the article
}

treatment and ultimately result in relapse and poor prognosis $[7,8]$. Therefore, it is necessary to develop appropriate combined reagents to solve drug resistance and enhance the sensitivity of EOC to cisplatin treatment.

Chemotherapy resistance is a key factor that limits the cure rate of ovarian cancer. The mechanisms underlying cancer cells resistance to cisplatin are not fully understood. It is acknowledged that various mechanisms are responsible for drug-resistance, including the decrease of the effective concentration of drugs in cells, the abnormalities of drug targets, and the abnormal regulation of cell apoptosis [9]. Currently, there are some ways to overcome the chemo-resistance, such as maintenance therapy, novel cytotoxic agents, modulation of apoptosis and combination therapy [10]. Natural medicine, with its small side effects and significant therapeutic effect, attracts a lot attention as a potential combination agent for cisplatin treatment. 
Luteolin is one of the most common flavonoid compound that is widely existed in various plants including peppermint, rosemary, thyme, pinophyte, and pteridophyta [11]. Numerous studies suggested that luteolin possesses a variety of pharmacological properties including anti-inflammatory, antiallergic, antioxidant, antimicrobial, immune regulation and anticancer activities $[11,12]$. Among all these properties, anti-tumor effect has attracted a lot of attention. Researchers have found that luteolin exerts anti-tumor activities via several mechanisms, including cell cycle arrest, apoptosis induction, angiogenesis and metastasis inhibition [13-16]. A previous study has demonstrated that luteolin can sensitize oxaliplatin-resistant colorectal cancer cells to chemotherapeutic drugs through the inhibition of the Nrf2 pathway [17]. Another study reported that luteolin can be used as a chemosensitizer to improve the therapeutic effect of tamoxifen in drug-resistant human breast cancer cells via the inhibition of cyclin E2 expression [18]. These results suggest that luteolin exhibits potential chemosensitivity property for various cancers. However, whether luteolin can increase the chemotherapy sensitivity of cisplatin-resistant ovarian cancer and the underlying mechanisms is rarely reported, which needs to be further studied.

In the current study, we investigated the synergistic effects of luteolin combined with cisplatin in drug-resistant ovarian cancer cell line CAOV3/DDP both in vitro and in vivo, and tried to explore associated molecular mechanisms.

\section{Materials and methods}

\section{Reagents and cell lines}

Luteolin was bought from Jin Sui Biological Technology (Shanghai, China). It was dissolved in DMSO as a stock of $500 \mathrm{mM}$ and stored at $-20{ }^{\circ} \mathrm{C}$. Cisplatin was purchased from QILU Pharmaceutical (Shandong, China). Human drug-resistant ovarian cancer cell line, CAOV3/ DDP were obtained from the Shanghai Sixin Biotechnology company (Shanghai, China) and maintained in RPMI1640 (Gibco, Grand Island, NY, USA) containing 10\% fetal bovine serum (Gibco, Grand Island, NY, USA). The cells were incubated at $37{ }^{\circ} \mathrm{C}$ in a humidified atmosphere with $5 \% \mathrm{CO}_{2}$.

\section{Cell proliferation assay}

Cell proliferation was measured using Cell Counting Kit-8 (CCK-8; Dojindo Molecular Technologies, Inc., Kumamoto,Japan). Briefly, CAOV3/DDP cells $\left(5 \times 10^{3}\right)$ were seeded into 96-well plates and allowed for adhesion overnight. Then the cells were administrated with eight treatments as follows: control (culture medium); low-dose of luteolin $(10 \mu \mathrm{M})$; medial-dose of luteolin $(50 \mu \mathrm{M})$; high-dose of luteolin $(100 \mu \mathrm{M})$; CDDP $(2 \mu \mathrm{g} / \mathrm{ml})$; CDDP $(2 \mu \mathrm{g} / \mathrm{ml})+$ low-dose of luteolin $(10 \mu \mathrm{M})$; CDDP $(2 \mu \mathrm{g} / \mathrm{ml})+$ medial-dose of luteolin $(50 \mu \mathrm{M})$; CDDP $(2 \mu \mathrm{g} / \mathrm{ml})+$ high-dose of luteolin $(100 \mu \mathrm{M})$. After $48 \mathrm{~h}$ treatment, the culture medium was removed and CCK- 8 was added according to the manufacturer's instruction. Then the cells were incubated for $1-4 \mathrm{~h}$ at $37^{\circ} \mathrm{C}$ and the absorbance was detected at $450 \mathrm{~nm}$ using a microplate reader. Cell proliferation was calculated as follows:

Cell proliferation $(\%)=[(\mathrm{OD}$ of experiment group $-\mathrm{OD}$ of blank) / (OD of control group - OD of blank)] $\times 100 \%$.

\section{Apoptosis analysis}

Cell apoptosis was detected using Annexin V-FITC Apoptosis Detection Kit (BD Pharmingen, Franklin Lakes, NJ, USA). Cells $\left(2 \times 10^{4}\right)$ were seeded into 6 -well plates and treated with various concentration of luteolin $(0,10,50$, $100 \mu \mathrm{M}$ ) or CDDP alone or in combination for $48 \mathrm{~h}$. Then both the adherent and floating cells were harvested and stained according to the manufacturer's protocol. The apoptosis rate was analyzed by flow cytometry.

\section{Wound-healing assay}

Cell migration ability was measured by wound-healing assay. Briefly, cells were seeded into 6-well plates and allowed to grow to a monolayer. Subsequently, a straight scratch was generated across the plate using a $200 \mu \mathrm{l} \mathrm{pi-}$ pet tip. The cells were washed with PBS and incubated with various concentration of luteolin $(0,10,50$, $100 \mu \mathrm{M}$ ) and CDDP alone or in combination (dissolve the chemicals in serum-free culture medium). Wound healing was observed and photographed at 0 and $48 \mathrm{~h}$.

\section{Matrigel invasion assay}

The Matrigel was diluted in serum-free RPMI-1640 (RPMI-1640: Matrigel =8:1) and added into the upper chamber. After treatment with various concentrations of luteolin $(0,10,50,100 \mu \mathrm{M})$ and CDDP alone or in combination for $48 \mathrm{~h}$, the cells $\left(5 \times 10^{4}\right)$ were trypsinized and collected. $5 \times 10^{4}$ cells in $200 \mu \mathrm{l}$ serum-free medium were seeded into the upper chamber. The lower chamber was filled with $600 \mu \mathrm{l}$ complete medium containing $10 \%$ FBS. After incubation for $48 \mathrm{~h}$, the invaded cells were stained with crystal violet and pictured under a microscope at x100 magnification.

\section{qRT-PCR}

After treatment, the medium was removed and the cells were washed with PBS. The total RNA of each group was extracted using TRIzol (Invitrogen, California, USA). Then the RNA was reversely transcribed to cDNA using the PrimeScript ${ }^{\text {Tu }}$ RT Reagent kit (Takara, Dalian, China) according to the manufacturer's instruction. The qPCR was performed using a SYBR Premix Ex Taq (Tli RNaseH Plus) in Applied Biosystem 7300 (Applied 
Biosystems, Foster city, CA, USA). The BCL-2 mRNA expression was analyzed using the $2-\Delta \Delta C q$ method taking $\beta$-Actin as reference. The gene primer sequences were shown in Table 1.

\section{Western blot}

CAOV3/DDP cells were seeded into 6-well plates $\left(2 \times 10^{5} /\right.$ well),and treated with increasing doses of luteolin $(0,10,50$, $100 \mu \mathrm{M})$ or cisplatin $(2 \mu \mathrm{g} / \mathrm{ml})$ or both for $48 \mathrm{~h}$. Then, the cells were harvested, and total proteins were extracted using cell lysis buffer (1 mM PMSF, $50 \mathrm{mM}$ Tris (pH 8.1), $1 \%$ SDS, sodium pyrophosphate, $\beta$-glycerophosphate, sodium orthovanadate, sodium fluoride, EDTA, leupeptin and other inhibitors) (Beyotime Biotechnology, Shanghai, China. No. P0013G). The protein concentration was detected using BCA assay (Mai Bio Co., Ltd.). $20 \mu \mathrm{g}$ proteins of each group were separated on SDS-PAGE, and then transferred onto PVDF membranes (Millipore Corp., Bedford, MA, USA). Membranes were blocked with 5\% non-fat dry milk, and probed with primary antibodies against Bax (1:4000, Cell Signaling Technology, USA), Bcl-2 (1:4000, Cell Signaling Technology, USA), and $\beta$-Actin (1:5000, ProteinTech Group, Inc., USA) at $4{ }^{\circ} \mathrm{C}$ overnight. Then the membrane was washed with PBS and incubated with HRP-conjugated secondary antibodies (1:5000) for $1 \mathrm{~h}$ at room temperature. Finally, the blots were imaged with ECL (EMD Millipore).

\section{In vivo xenograft experiment}

Female BALB/c nude mice (5-6 weeks old) were obtained from the Shanghai Experimental Animal Center. Animals were raised in pathogen-free conditions at $22^{\circ}$ C, $50 \%$ humidity. Animal experiments were approved by the Institutional of Animal Care and Use Committee of Jinshan Hospital, Fudan University. The cisplatin resistant cell line CAOV3/DDP $\left(5 \times 10^{6}\right.$ cells $)$ in a volume of $100 \mu \mathrm{l}$ of PBS were inoculated in the subcutaneous tissue of the nude mice. Two weeks after implantation, the tumors were visible and the mice were randomly allocated into 8 groups (6 mice per group): (1) control group (normal saline); (2) luteolin low-dose (10 mg.kg$\left.{ }^{1} \cdot \mathrm{d}^{-1}\right)$ group; (3) luteolin medial-dose $\left(20 \mathrm{mg} \cdot \mathrm{kg}^{-1} \cdot \mathrm{d}^{-1}\right)$ group; (4) luteolin high-dose (40 $\left.\mathrm{mg} \cdot \mathrm{kg}^{-1} \cdot \mathrm{d}^{-1}\right)$ group; (5) CDDP (3 mg. $\left.\mathrm{kg}^{-1} \cdot \mathrm{d}^{-1}\right)$ group; (6) CDDP $\left(3 \mathrm{mg} \cdot \mathrm{kg}^{-1} \cdot \mathrm{d}^{-}\right.$ $\left.{ }^{1}\right)$ plus luteolin low-dose $\left(10 \mathrm{mg} \cdot \mathrm{kg}^{-1} \cdot \mathrm{d}^{-1}\right)$ group; (7) CDDP $\left(3 \mathrm{mg} \cdot \mathrm{kg}^{-1} \cdot \mathrm{d}^{-1}\right)$ plus luteolin medial-dose

Table 1 Primer sequences for genes

\begin{tabular}{ll}
\hline Gene & Primer Sequences \\
\hline BCL-2 & F: 5'-AACATCGCCCTGTGGATGAC-3' \\
& R: 5'-AGAGTCTTCAGAGACAGCCAGGAG-3' \\
B-Actin & F: 5'-CATTGCCGACAGGATGCAG-3' \\
& R: 5'-CTCGTCATACTCCTGCTTGCTG-3' \\
\hline
\end{tabular}

(20 mg. $\mathrm{kg}^{-1} \cdot \mathrm{d}^{-1}$ ) group; (8) CDDP $\left(3 \mathrm{mg} \cdot \mathrm{kg}^{-1} \cdot \mathrm{d}^{-1}\right)$ plus luteolin high-dose $\left(40 \mathrm{mg} \cdot \mathrm{kg}^{-1} \cdot \mathrm{d}^{-1}\right)$ group. The CDDP were intraperitoneal injected once daily, and luteolin were given by gavage once daily for 5 days. The tumor volume was measured three times a week. Three weeks after treatment, the mice were sacrificed, and the tumor volume and weight were measured. The tumor tissues were used for histopathologic examination.

\section{TUNEL}

Tumor paraffin tissue sections were processed with TUNEL assay to analyze apoptosis. The procedure was performed according to instructions of the TUNEL kit (KeyGen, Nanjing, China). The samples were observed under a microscope at $\times 100$ magnification. The apoptotic cells were counted in three random fields for each sample, and the apoptosis percentage was calculated as follows: (Number of TUNEL-positive cells/Total number of cells in the field) $\times 100 \%$.

\section{Drug combination effect analysis}

Combination effect between the luteolin and cisplatin was analyzed by the Zheng-Jun Jin method [19-21]. In this method, the combination rate was evaluated by the inhibition rate via the $\mathrm{Q}$ value. The formula for the $\mathrm{Q}$ value is: $\mathrm{Q}$ $=\mathrm{Ea}+\mathrm{b} /(\mathrm{Ea}+\mathrm{Eb}-\mathrm{Ea} \times \mathrm{Eb})$, where $\mathrm{Ea}+\mathrm{b}, \mathrm{Ea}$, and $\mathrm{Eb}$ are the inhibition rate of the combination group, drug a and drug $\mathrm{b}$, respectively. $\mathrm{Q}=1$ would mean simple addition; $\mathrm{Q}>\mathrm{l}$, synergism or potentiation, $\mathrm{Q}<1$, antagonism.

\section{Statistical analysis}

All the experiments were repeated three times. The data were presented as mean $\pm \mathrm{SD}$. The difference between indicated groups were analyzed using Student's t-test. $P$ $<0.05$ was considered be statistically significant.

\section{Results \\ Luteolin dose dependently enhanced the proliferation inhibition effect of cisplatin in CAOV3/DDP cells}

Cells were treated with various doses of luteolin $(0,10,50$, and $100 \mu \mathrm{M})$, cisplatin $(2 \mu \mathrm{g} / \mathrm{ml})$ alone or in combination for $48 \mathrm{~h}$ and then cell proliferation was monitored by CCK-8 assay. As shown in Fig 1a, b, luteolin alone inhibited the cell proliferation of CAOV3/DDP cells in a concentration- dependent manner. Cells treated with combination of cisplatin $(2 \mu \mathrm{g} / \mathrm{ml})$ and luteolin $(10,50,100 \mu \mathrm{M})$ for $48 \mathrm{~h}$ showed a more significant proliferation decrease in contrast with either luteolin or cisplatin alone. These results suggested that luteolin enhanced the proliferation inhibition effect of cisplatin in CAOV3/DDP cells in a concentration-dependent manner. To further investigate the nature of the combination effect between luteolin and cisplatin on CAOV3/DDP cells, the $\mathrm{Q}$ value was calculated based on the CCK-8 assay. As shown in Table 2, the data 


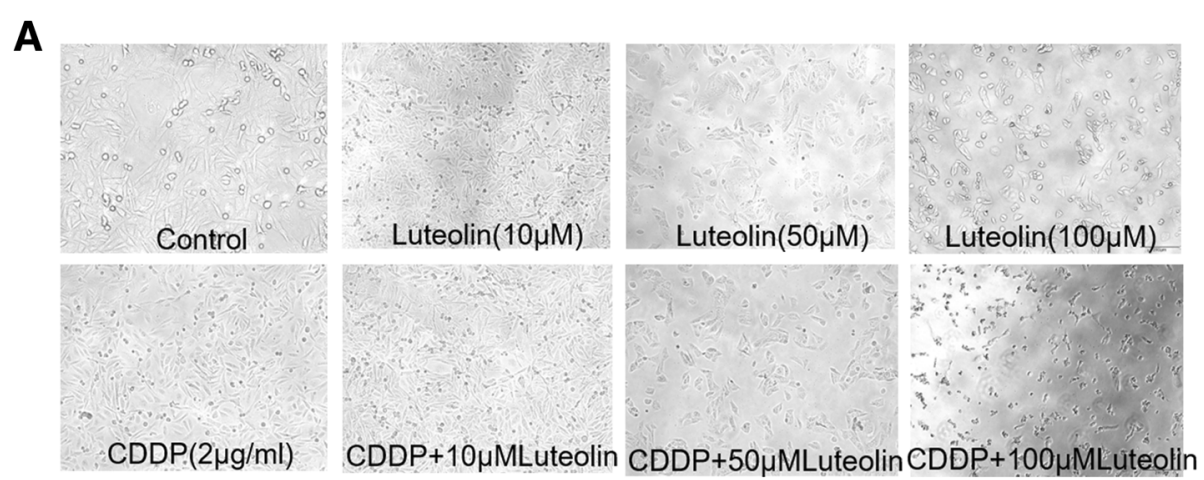

B

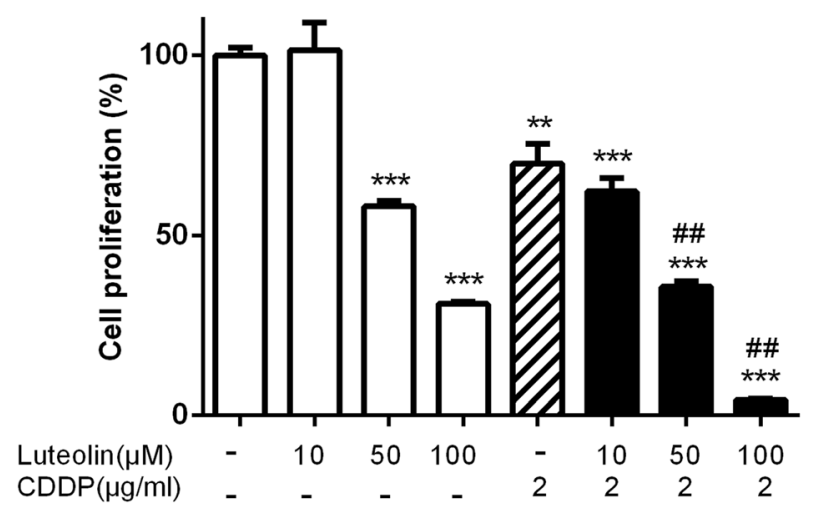

Fig. 1 Effects of luteolin and cisplatin on the proliferation of CAOV3/DDP cells. Cells were treated with indicated concentrations of luteolin or cisplatin or both for $48 \mathrm{~h}$, and cell proliferation was measured by CCK-8 assay. a Representative morphological changes of indicated treatment at $\times 200$ magnification; $\mathbf{b}$ Dose response curves indicated significant reduction of cell proliferation in comparison to normal control. Data were represented as mean \pm standard error of three independent experiments. ${ }^{* *} P<0.01$, ${ }^{* * *} P<0.001$, vs. control; \#\# $P<0.01$ vs. cisplatin. CDDP: cisplatin

suggested that luteolin exhibited an additive or synergistic effect when combined with cisplatin.

\section{Luteolin enhanced cisplatin induced apoptosis in CAOV3/ DDP cells}

As luteolin promoted cisplatin induced cell proliferation inhibition, we further determined whether the

Table 2 Luteolin increased the sensitivity of CAOV3/DDP cells to cisplatin. The $\mathrm{Q}$ value was calculated to evaluate the effect of the combination of the two drugs. The inhibition rates were measured by CCK-8 assay. CDDP combined with luteolin $(100 \mu \mathrm{M})$ showed a synergistic inhibitory effect on the proliferation of CAOV3/DDP cells $(Q=1.22 \pm 0.04,>1, P<0.01)$. The data were expressed as the mean \pm S.D. in triplicate

\begin{tabular}{lll}
\hline Drugs & Inhibition rate (\%) & Q value \\
\hline Luteolin $(100 \mu \mathrm{M})$ & $69.1 \pm 0.55$ & \\
Luteolin $(50 \mu \mathrm{M})$ & $42.0 \pm 1.20$ & \\
Luteolin $(10 \mu \mathrm{M})$ & $-1.5 \pm 6.26$ & \\
CDDP $(2 \mu \mathrm{g} / \mathrm{ml})$ & $30.2 \pm 4.54$ & $1.22 \pm 0.04$ \\
Luteolin $(100 \mu \mathrm{M})+\operatorname{CDDP}(2 \mu \mathrm{g} / \mathrm{ml})$ & $95.7 \pm 0.24$ & $1.08 \pm 0.06$ \\
Luteolin $(50 \mu \mathrm{M})+\operatorname{CDDP}(2 \mu \mathrm{g} / \mathrm{ml})$ & $64.3 \pm 1.22$ & $1.36 \pm 0.41$ \\
Luteolin $(10 \mu \mathrm{M})+\operatorname{CDDP}(2 \mu \mathrm{g} / \mathrm{ml})$ & $37.9 \pm 3.02$ & \\
\hline
\end{tabular}

combination treatment could exert synergic induction on cell apoptosis. Cell apoptosis was evaluated by flow cytometry following treatment of luteolin $(0,10,50$, and $100 \mu \mathrm{M})$, CDDP $(2 \mu \mathrm{g} / \mathrm{ml})$ alone or the combined treatments. As shown in Fig. 2a-b, no significant apoptosis was observed in cells treated with $10 \mu \mathrm{M}$ luteolin. Treatments with higher doses $(50 \mu \mathrm{M}$ and $100 \mu \mathrm{M})$ of luteolin induced evident cell apoptosis, and the apoptosis rates were $4.29 \%$ and $14.39 \%$ respectively. Cisplatin alone caused about $3.11 \%$ of apoptosis. When cells were treated with both luteolin and cisplatin, the apoptosis rate increased significantly. The apoptosis rates of luteolin $(10 \mu \mathrm{M})+$ cisplatin, luteolin $(50 \mu \mathrm{M})+$ cisplatin and luteolin $(100 \mu \mathrm{M})+$ cisplatin group were $3.41 \%, 5.48 \%$ and $24.75 \%$, respectively.

\section{Luteolin and cisplatin decreased Bcl-2 expression synergistically}

Next, to explore the underlying mechanisms involved in the sensitization effect of luteolin on cisplatin-induced apoptosis, we measured the expression level of the anti-apoptotic regulator, Bcl-2, by qRT-PCR and western blotting, and the pro-apoptotic protein Bax through 


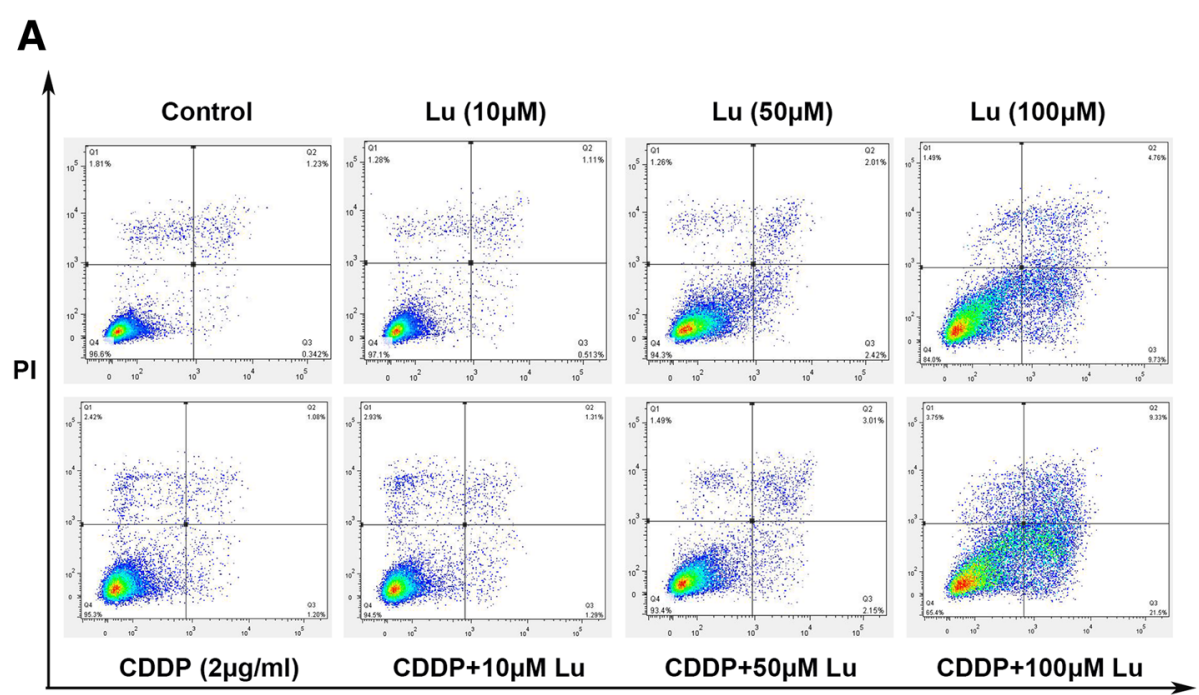

B

FITC Annexin V

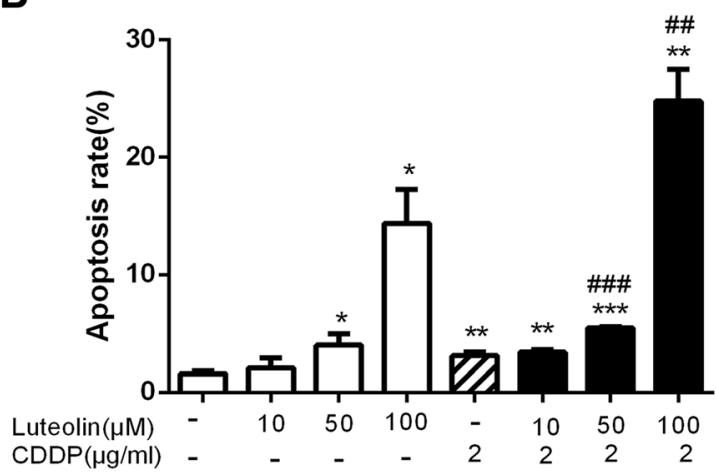

Fig. 2 Luteolin induced cell apoptosis and enhanced cisplatin-induced apoptosis of CAOV3/DDP cells. Cells were treated with luteolin or cisplatin or in combination for $48 \mathrm{~h}$, and then the apoptosis was detected by Annexin V/PI. a Flowcytometric analysis; $\mathbf{b}$ Statistical analysis for apoptosis ratio in each group. Data were represented as mean \pm SD of three independent experiments. ${ }^{*} P<0.05, * * P<0.01,{ }^{* * *} P<0.001$, vs. control; \#\# $P$ $<0.01$, \#\#\# $P<0.001$ vs. cisplatin. CDDP: cisplatin. CDDP combined with luteolin $(100 \mu \mathrm{M})$ showed a synergistic effect on the apoptosis induction of $C A O V 3 / D D P$ cells $(Q=1.46 \pm 0.1,>1, P<0.01)$

western blotting assay. As shown in Fig. 3, luteolin at high dose of $100 \mu \mathrm{M}$ decreased the Bcl-2 mRNA level and protein expression, and cisplatin alone also decreased the Bcl-2 level. Moreover, the Bcl-2 expression was decreased further in the combined treatment of luteolin and cisplatin. However, the Bax protein expression didn't show significant change in all the groups (data not shown). These results suggested that luteolin enhanced the antitumor response of cisplatin by modulating apoptosis pathway.

\section{Luteolin combined with CDDP inhibited migration and invasion in CAOV3/DDP cells}

To determine whether combination treatment affected cell migration and invasion ability, we then treated CAOV3/DDP cells with luteolin or cisplatin or combination of both by wound-healing assay and Matrigel invasion assay. The results (Figs. 4 and 5) showed that, luteolin alone inhibited cell migration and invasion in a dose-dependent manner, and the combination of CDDP and luteolin evidently decreased cell migration and invasion compared with either single agent treatment. These results demonstrated that luteolin could suppress migration and invasion and enhance sensitivity to CDDP in CAOV3/DDP cell line.

\section{Luteolin enhanced the anticancer effect of CDDP on ovarian cancer in vivo}

To determine whether luteolin could enhance the cytotoxicity of CDDP in vivo, we established an ovarian cancer model in nude mice and investigated the therapeutic effects of luteolin alone or in combination with CDDP. The results showed that luteolin combined with CDDP notably impeded the tumor growth compared with cisplatin alone, exhibited as decreased tumor volume (Fig. 6a) and declined tumor weight (Fig. 6b). According 


\section{A}

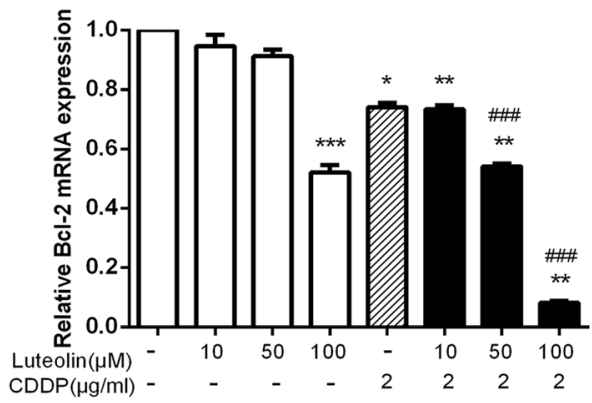

B

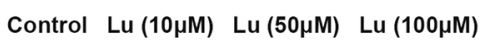
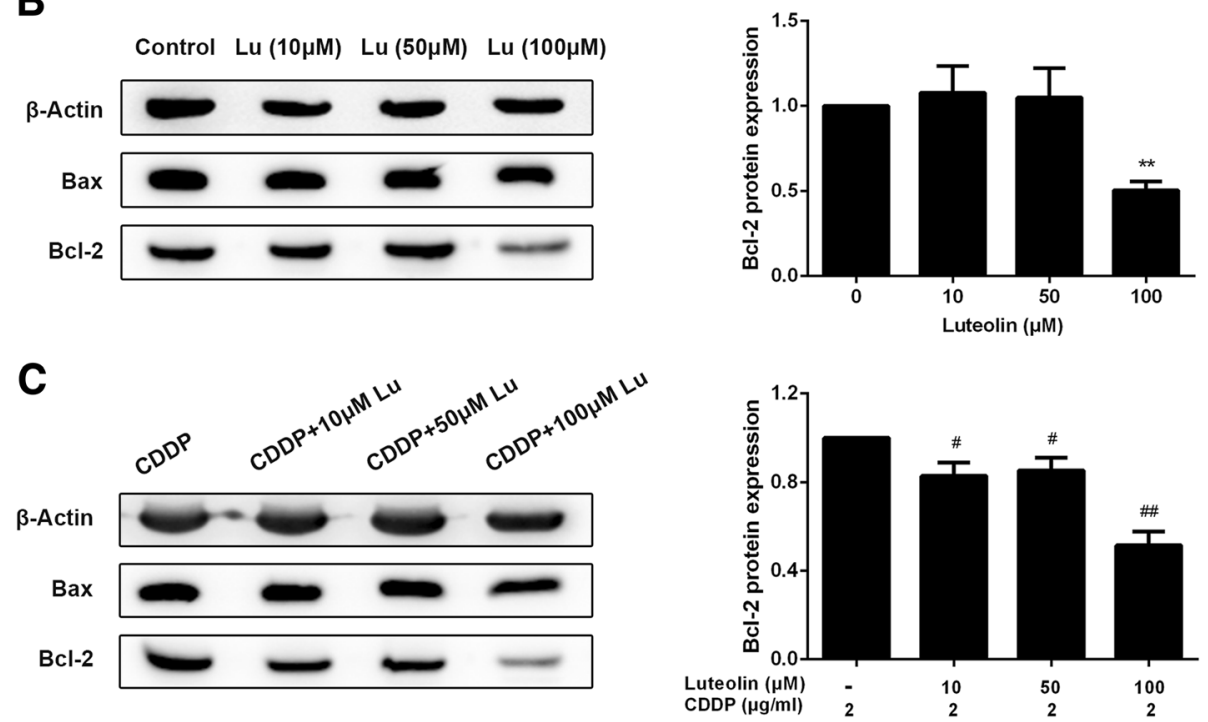

Fig. 3 Effects of luteolin in combination with cisplatin on expression of apoptosis related proteins. CAOV3/DDP cells were treated with various concentrations of luteolin or cisplatin or the combination of both for $48 \mathrm{~h}$, and then the expression of Bax, Bcl-2 was assessed by qRT-PCR and western blotting. a Relative Bcl-2 mRNA expression was normalized to $\beta$-actin; $\mathbf{b}$ Bax and Bcl-2 protein expressions of cells treated with luteolin; $\mathbf{c}$ $\mathrm{Bax}$ and $\mathrm{BCl}-2$ protein expressions of cells treated with the combination of cisplatin and increasing doses of luteolin. ${ }^{*} P<0.05,{ }^{* *} P<0.01$, ${ }^{* * *}$ $P<0.001$, vs. control; \# $P<0.05$, \#\# $P<0.01$, \#\#\# $P<0.001$ vs. cisplatin. CDDP: cisplatin. CDDP combined with luteolin $(50,100 \mu \mathrm{M})$ indicated a synergistic inhibitory effect on the $\mathrm{BCl}-2$ expression of CAOV3/DDP cells $(\mathrm{Q}=1.43 \pm 0.16$ and $1.50 \pm 0.09$, respectively, $>1, P<0.01$ and $P<0.001$, respectively)

to the tumor weight, we calculated the inhibition rate of each group, the combination tumor growth inhibition rate also showed a synergistic or additive effect (Table 3). These results were in consistent with in vitro experiments. Collectively, these results indicated that luteolin enhanced CDDP sensitivity of ovarian cancer in vivo.

\section{Combined treatment of CDDP with luteolin increases xenograft tumor cell apoptosis}

Further, we examined the effect of combined treatment of CDDP with luteolin on tumor cell apoptosis through TUNEL assay in the tumor tissues isolated from the 8 groups of mice above. As shown in Fig. 7, luteolin alone induced apoptosis at doses of $20 \mathrm{mg} \cdot \mathrm{kg}^{-1} \cdot \mathrm{d}^{-1}$ and $40 \mathrm{mg} \cdot \mathrm{kg}^{-1} \cdot \mathrm{d}^{-1}$ (the apoptosis rates were $0.51 \%$ and $1.70 \%$, respectively) while the lower dose at $10 \mathrm{mg} \cdot \mathrm{kg}^{-}$ ${ }^{1} \cdot \mathrm{d}^{-1}$ didn't show significant effect compared with control group (apoptosis rate: $0.24 \%$ ). The results also revealed an increased apoptosis rate by combined treatment compared with cisplatin treatment alone. The apoptosis rates of CDDP, CDDP plus low dose of luteolin, CDDP plus medial dose of luteolin and CDDP plus high dose of luteolin were $1.24 \%, 1.59 \%, 3.03 \%$, and $8.61 \%$, respectively. This further demonstrated that luteolin enhanced antitumor effect of CDDP by increasing apoptosis of tumor cells.

\section{Discussion}

Cisplatin is one of the most effective therapeutic agents widely used in clinic for the treatment of EOC. However, drug resistance is a major problem that limits its clinical application. Therefore, combination treatment with new sensitizing agents is an effective strategy to overcome cisplatin resistance [10]. Luteolin, a flavonoid that has 
A

Control

Lu $(10 \mu \mathrm{M})$

Lu $(50 \mu \mathrm{M})$

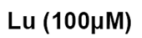
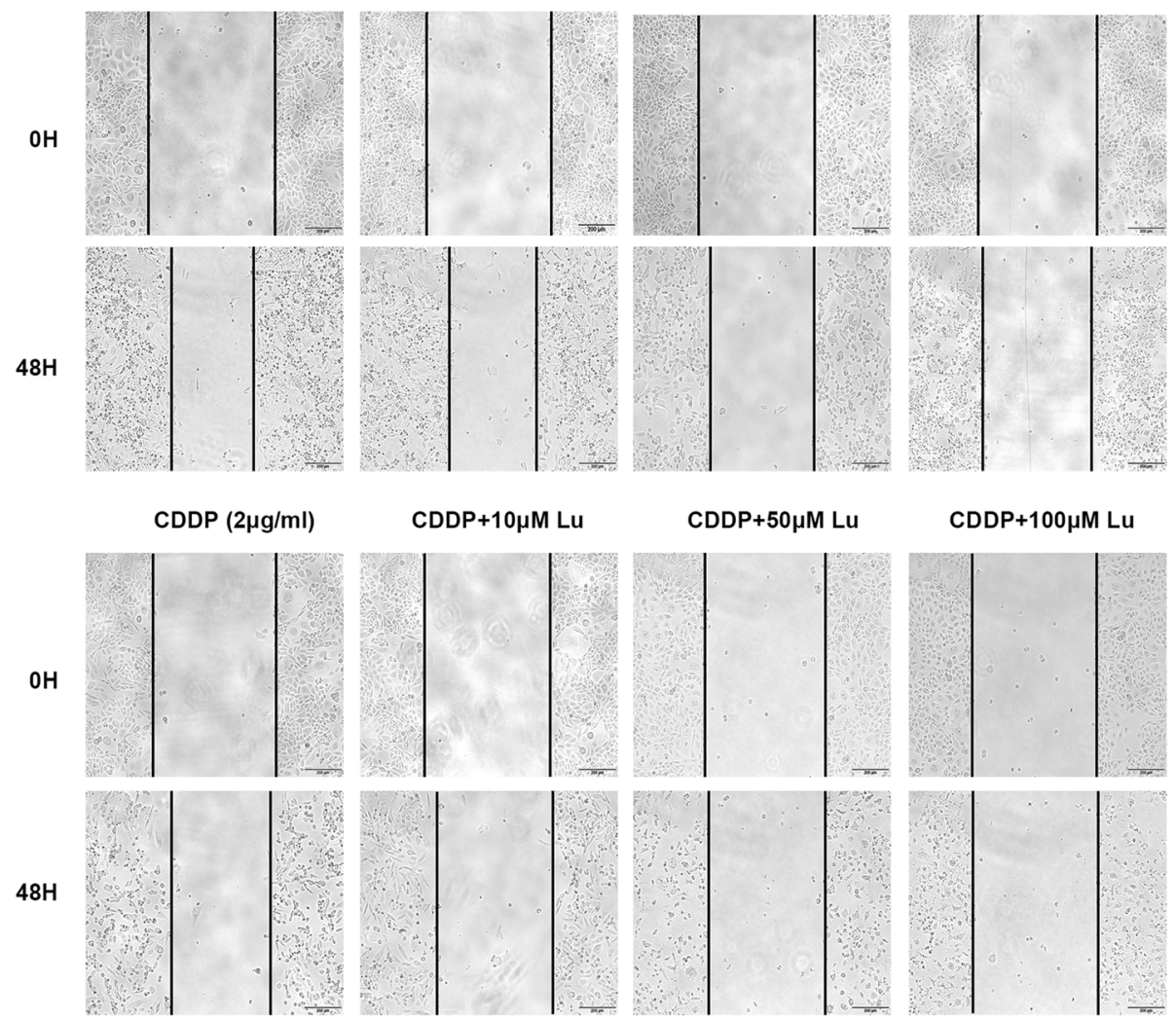

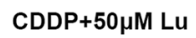

$\mathrm{CDDP}+100 \mu \mathrm{M} L \mathrm{Lu}$
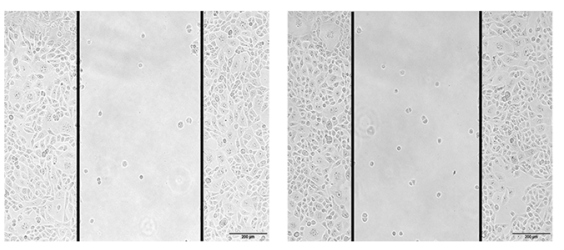

B

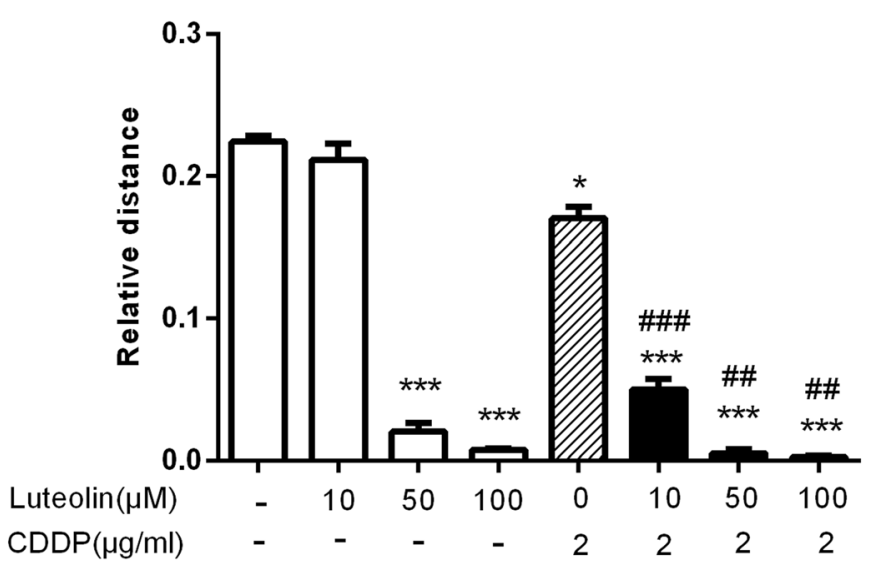

Fig. 4 Luteolin inhibited cell migration and enhanced cisplatin-induced migration suppression in CAOV3/DDP cells. Migratory ability of CAOV3/DDP cells treated with increasing doses of luteolin or cisplatin or the combination of both agents was tested using wound-healing assay. a The gap of indicated groups was imaged at 0 and $48 \mathrm{~h}$ (magnification, $\times 100$ ); $\mathbf{b}$ Relative migration distance of three independent experiments. ${ }^{*} P<0.05$, ${ }^{* * *} P<$ 0.001 , vs. control; \#\# $P<0.01$, \#\#\# $P<0.001$ vs. cisplatin. CDDP: cisplatin. CDDP combined with luteolin $(10,100 \mu \mathrm{M})$ showed a synergistic inhibitory effect on the migratory ability of CAOV3/DDP cells $(Q=2.91 \pm 0.97$ and $1.02 \pm 0.003$, respectively, $>1, P<0.05$ and $P<0.01$, respectively)

been identified in many plants, has demonstrated in numbers studies to exhibit chemopreventive or chemosensitising properties against various human cancers. In the current study, we provide experimental evidence both in vivo and in vitro that luteolin is able to enhance the therapeutic potential of cisplatin in ovarian cancer.
In the current study, firstly, we evaluated the effect of luteolin or cisplatin or the combination of both on the cell proliferation in human cisplatin-resistant ovarian cancer CAOV3/DDP cells. We found that luteolin alone inhibited the cell proliferation in a dose-dependent manner, and co-treatment with both agents could further 
A
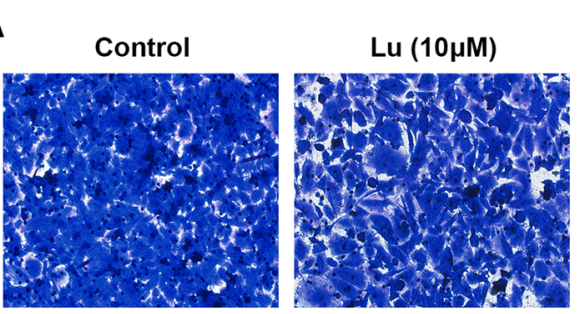

$\mathrm{Lu}(50 \mu \mathrm{M})$
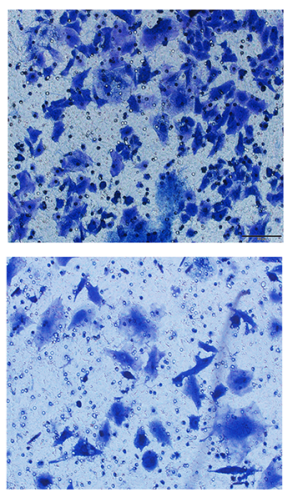

CDDP+50 $\mu \mathrm{M} \mathrm{Lu}$

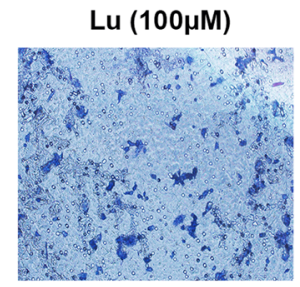

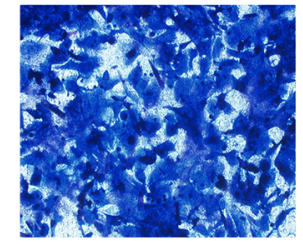

CDDP $(2 \mu \mathrm{g} / \mathrm{ml})$

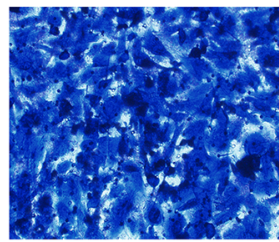

CDDP+10 $\mu \mathrm{M} \mathrm{Lu}$

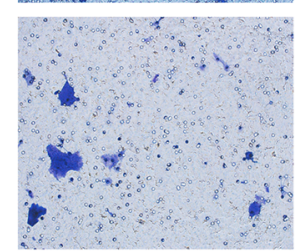

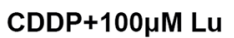

B

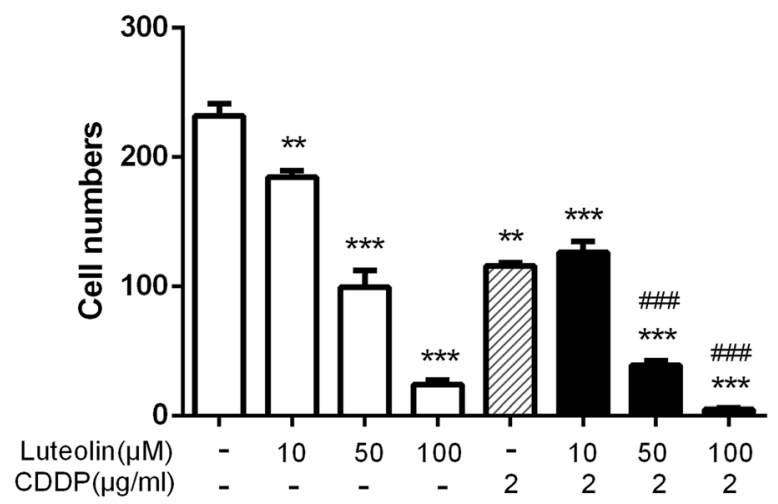

Fig. 5 Luteolin suppressed cell invasion and enhanced cisplatin-induced suppression of invasion in CAOV3/DDP cells. Invasion ability of CAOV3/ DDP cells of indicated treatments was measured using Matrigel invasion assay. a The image of invaded cells (magnification, $\times 200$ ); $\mathbf{b}$ Numbers of invaded cells in each group of three independent experiments. ${ }^{*} P<0.01,{ }^{* *} P<0.001$, vs. control; \#\#\# $P<0.001$ vs. cisplatin. CDDP: cisplatin. CDDP combined with luteolin $(50,100 \mu \mathrm{M})$ showed a synergistic inhibitory effect on the invasion of CAOV3/DDP cells $(\mathrm{Q}=1.06 \pm 0.02$ and $1.03 \pm$ 0.007 , respectively, $>1, P<0.05$ and $P<0.01$, respectively)

decrease cell proliferation. These results suggested that luteolin could exert synergistic anti-proliferation effect with cisplatin in CAOV3/DDP cells.

Apoptosis inhibition is one of the main mechanisms responsible for the resistance of chemotherapy [22]. Cisplatin is one of the most effective drugs for the treatment of ovarian cancer, and the mechanism involved in the process of its cytotoxicity include survival inhibition and apoptosis induction. Once the apoptotic pathway is blocked, tumor cells acquire resistance to pro-apoptotic effect of cisplatin, which reduces the antitumor effect of cisplatin [23]. Therefore, inhibition of apoptosis is an effective strategy to overcome the drug resistance and promote the anti-tumor effect of cisplatin [24]. Luteolin has been reported to induce apoptosis in various cancer cells such as human cervical cancer cells [13], esophageal carcinoma cells [25] and colorectal cancer cells [26]. Our study found that the single treatment with luteolin could dose-dependently induce apoptosis in CAOV3/DDP cells, when combined with cisplatin, luteolin could significantly enhance cisplatin-induced cell apoptosis, indicating that luteolin enhanced the sensitivity of cisplatin, in part, through apoptosis induction.

The BCL-2 protein family plays a key role in the regulation of cell apoptosis. The BCL-2 protein family can be divided into three different subfamilies, including pro-survival factions such as BCL-2, MCL1 and $\mathrm{BCL}-\mathrm{XL}$, which inhibit the apoptosis process, and two pro-apoptotic subfamilies, the death effectors BAX and BAK and the BH3-only proteins such as BID, BIM and PUMA, which contribute to cell apoptosis [27-29]. Consequently, the ratio of $\mathrm{Bcl}-2 / \mathrm{Bax}$ is an essential factor to determine whether a tumor cell commits apoptosis or not. Overexpression of $\mathrm{Bcl}-2$ can inhibit cell apoptosis, lead to resistance to cisplatin, and result in poor prognosis of cancer patients. Recent study has demonstrated that $\mathrm{Bcl}-2$ is overexpressed in ovarian cancer $[30,31]$ and has a significant positive correlation with sensitivity to cisplatin in ovarian cancer cells [32]. Therefore, targeting $\mathrm{Bcl}-2$ may provide an effective therapeutic method 


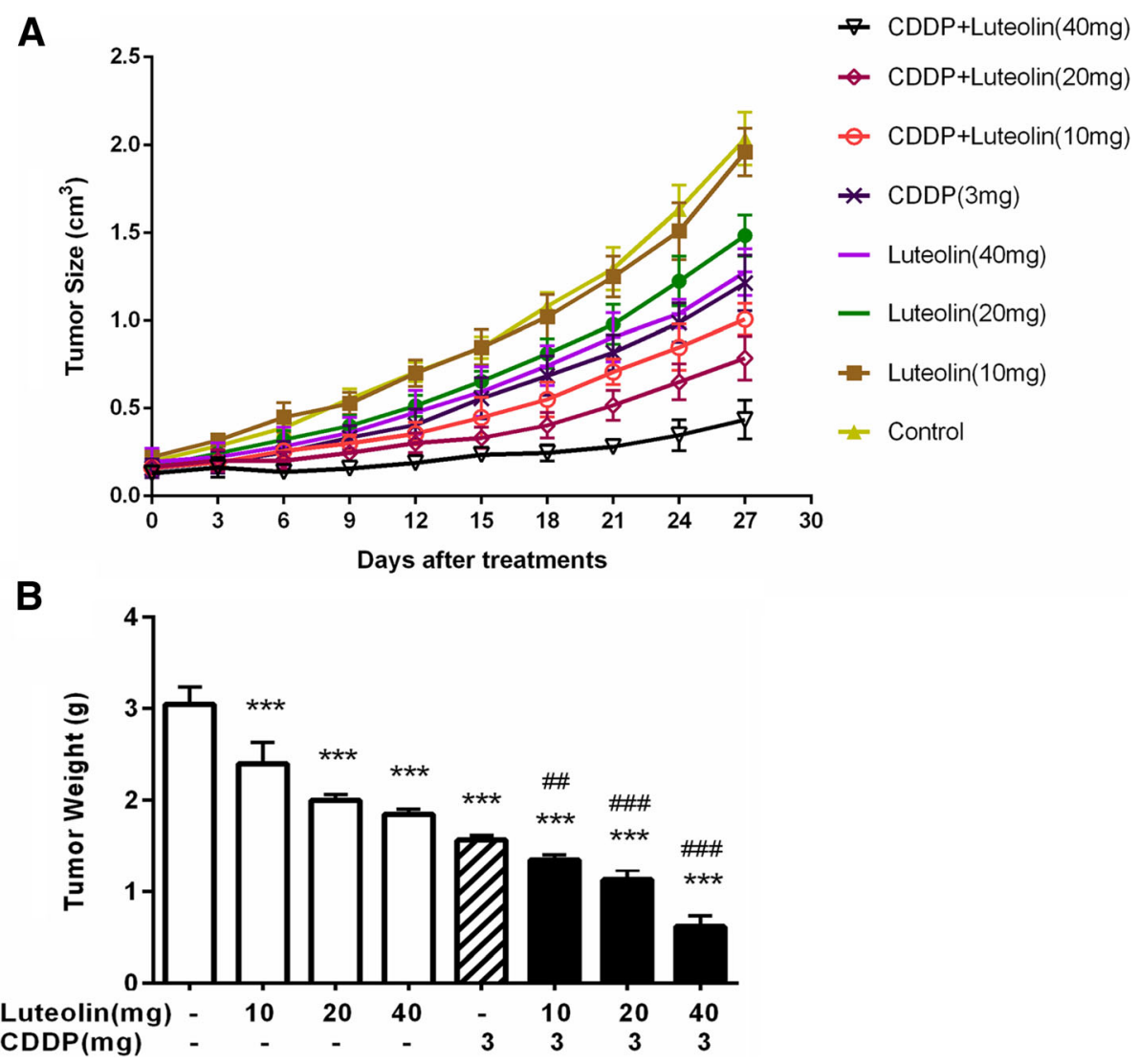

Fig. 6 Luteolin enhanced antitumor efficacy of CDDP against xenograft model of ovarian cancer. Xenograft mice were treated with various doses of luteolin or cisplatin or in combination. a The tumor volume was measured three times a week. $(n=6)$. $\mathbf{b}$ Three weeks after treatment, the mice were sacrificed, and tumor weight were measured. $(n=6)$. ${ }^{* * *} P<0.001$, vs. control; \#\# $P<0.01$, \#\#\# $P<0.001$ vs. cisplatin. CDDP: cisplatin

to solve drug resistance in ovarian cancer. It was previously reported that luteolin could decrease Bcl-2 expression in various cancer cells [33]. In the current study, results from qRT-PCR showed that luteolin at high concentration $(100 \mu \mathrm{M})$ could significantly decrease the $\mathrm{Bcl}-2$

Table 3 Luteolin increased the sensitivity of xenograft model of ovarian cancer to cisplatin. The $\mathrm{Q}$ value was calculated to evaluate the effect of the combination of the two drugs. The inhibition rate in each group was measured by tumor weight reduction compared to the control group. CDDP combined with luteolin (40 mg) showed a synergistic inhibitory effect on the growth of xenograft tumor $(Q=1.16 \pm 0.03,>1, P<0.01)$. The data were expressed as the mean \pm S.D. in triplicate

\begin{tabular}{lll}
\hline Drugs & Inhibition rate (\%) & Q value \\
\hline Luteolin (40 mg) & $39 \pm 1.64$ & \\
Luteolin (20 mg) & $34.4 \pm 1.89$ & \\
Luteolin (10 mg) & $21.3 \pm 6.83$ & \\
CDDP (3 mg) & $48.6 \pm 1.55$ & \\
Luteolin (40 mg) + CDDP (3 mg) & $79.8 \pm 3.5$ & $1.16 \pm 0.03$ \\
Luteolin (20 mg) + CDDP (3 mg) & $62.8 \pm 3.09$ & $0.95 \pm 0.03$ \\
Luteolin (10 mg) + CDDP (3 mg) & $55.7 \pm 1.64$ & $0.94 \pm 0.05$ \\
\hline
\end{tabular}

mRNA level, and the combination of luteolin with cisplatin could evidently inhibit Bcl-2 expression compared with cisplatin alone. This suggests that the combined treatment induced cell apoptosis through the inhibition of Bcl-2 expression. The BCL-2 family proteins control the permeability of mitochondria and the release of cytochrome $\mathrm{c}$ to the cytoplasm, following the activation of a group of caspases, which proceeds apoptosis [27]. This suggests that mitochondrial apoptosis pathway may be involved, and further study should be focused on the pathway.

Our data also revealed the potent antitumor effect of luteolin with cisplatin in ovarian cancer in vivo. Single treatment with increasing doses of luteolin showed growth inhibition in xenograft tumor. In addition, tumor volume and weight were significantly decreased in mice of combination treatment group compared with cisplatin alone. What's more, the combination therapy synergistically induced more apoptosis than cisplatin, which is in consistent with in vitro study. These results further demonstrate that the inhibition of tumor growth was induced, in part, by the enhancement of cisplatin induced apoptosis. 

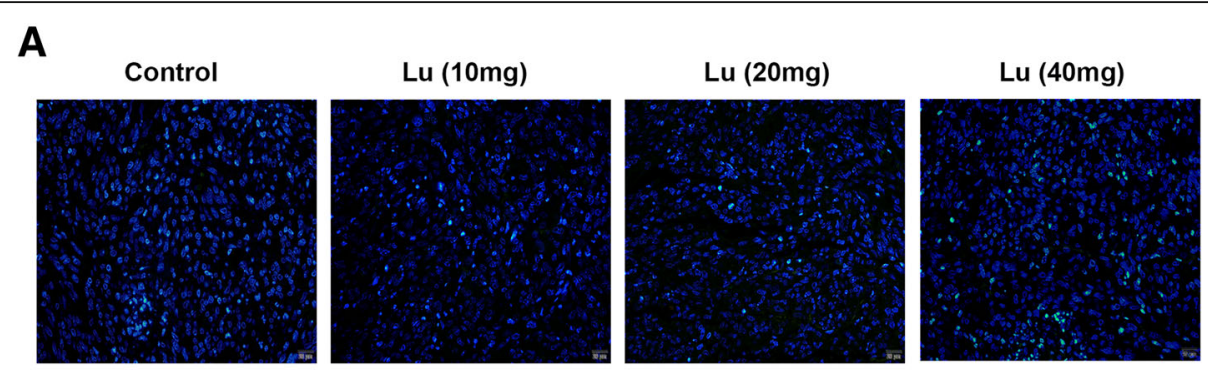

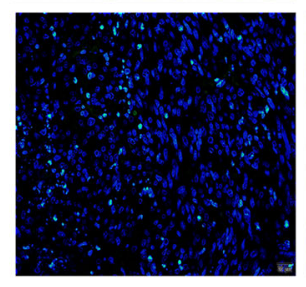

CDDP(3mg)

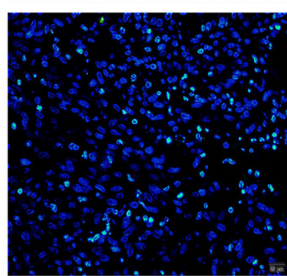

CDDP+10mg Lu

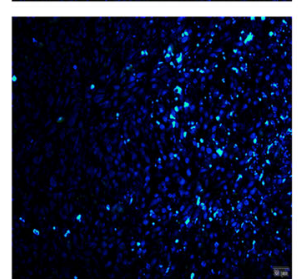

CDDP+20mg Lu

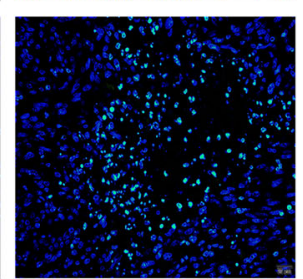

CDDP+40mg Lu

B

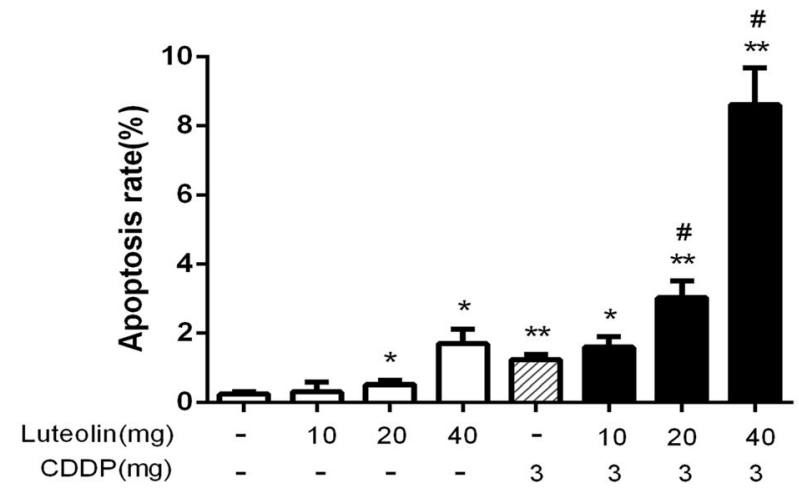

Fig. 7 Luteolin in combination with cisplatin enhanced apoptosis in vivo. Apoptosis of tumor sections were detected by TUNEL assay. a Representative images of apoptotic cells in each group (apoptotic cells in green and the cell nuclei in blue). $\mathbf{b}$ The tumor cell apoptosis rates of 8 groups were analyzed. * $P<0.05,{ }^{* *} P<0.01$, vs. control; $\# P<0.05$ vs. cisplatin. CDDP: cisplatin. CDDP combined with luteolin (20 mg, 40 mg) exhibited a synergistic effect on the apoptosis induction of xenograft tumor $(Q=1.73 \pm 0.03$ and $2.95 \pm 0.16$, respectively, $>1, P<0.01$ and $P<0.01$, respectively)

Ovarian cancer is highly susceptible to occur metastasis in late stage. In most patients, though appearance of the lesion is still localized in the ovary, subclinical metastasis may already exist in many parts of the peritoneal or omentum [34]. In addition, chemotherapy resistance leads to the decrease of chemotherapy sensitivity in ovarian cancer cells, and also enhance its malignant degree. It suggests that the occurrence of chemotherapy resistance is closely related to the promotion of invasion and metastasis in cancer cells $[35,36]$. Cancer metastasis involves several processes including adhesion, migration, and invasion. Targeting these processes provides effective strategy to enhance the chemosensitivity of cisplatin [37]. Luteolin has been proven to inhibit metastasis in various caner types such as breast cancer [38] and prostate cancer [39]. In our experiment, wound-healing assay and Matrigel invasion assay showed that luteolin exhibited a dose-dependent suppression on migration as well as invasion in CAOV3/DDP cells. Additionally, the inhibition effect became stronger when treated the cells with both increasing concentrations of luteolin and cisplatin than single agent treatment. These results indicate that the improved anticancer effect of cisplatin in CAOV3/DDP cells by luteolin is partially mediated through inhibition in cell migration and invasion.

In conclusion, our study shows that luteolin, a natural flavonoid, significantly enhances the anti-tumor effect of cisplatin in ovarian cancer both in vivo and in vitro. Combination of luteolin and cisplatin is more effective in suppressing CAOV3/DDP cell growth and metastasis. Luteolin could enhance cisplatin induced apoptosis in cisplatin-resistant ovarian cancer CAOV3/DDP cells via decreasing Bcl-2 expression. Our preliminary data provide experimental evidence for potential clinical application of luteolin as a novel chemosensitizer in the chemotherapy in ovarian cancer. 


\section{Acknowledgements}

We thank Longxiang Zhou, from Department of Science and Education, Jinshan branch of Shanghai Sixth People's Hospital, Shanghai Jiaotong University, and Guiping Gan, from Department of Obstetrics and Gynecology, Jinshan branch of Shanghai Sixth People's Hospital, Shanghai Jiaotong University, for their guidance and help in our work.

\section{Funding}

This study was supported by Science and Technology Innovation Fund Program of Jinshan District (2015-3-16)

\section{Availability of data and materials}

We declared that materials described in the manuscript, including all relevant raw data, will be freely available to any scientist wishing to use them for non-commercial purposes, without breaching participant confidentiality.

\section{Authors' contributions}

HW and YL both performed the study and wrote the manuscript, they contributed equally to this study. TQ reviewed and revised the article. ZW and $\mathrm{ZH}$ collected and analyzed the data. All authors read and approved the final manuscript.

\section{Ethics approval and consent to participate}

There was no human participants, human data or human tissue involved in this manuscript.

\section{Consent for publication}

This manuscript has been read and approved by all the authors, the requirements for authors have been met and each author believes that the manuscript represents honest work.

\section{Competing interests}

The authors declare that they have no competing interests.

\section{Publisher's Note}

Springer Nature remains neutral with regard to jurisdictional claims in published maps and institutional affiliations.

\section{Author details \\ 'Department of Obstetrics and Gynecology, Jinshan branch of Shanghai Sixth People's Hospital, Shanghai Jiaotong University, Shanghai, China. ${ }^{2}$ Department of Oncology, Jinshan Hospital, Fudan University, Shanghai, China. ${ }^{3}$ Department of Traditional Medicine, Jinshan branch of Shanghai Sixth People's Hospital, Shanghai Jiaotong University, Shanghai, China.}

Received: 12 April 2018 Accepted: 4 November 2018 Published online: 19 November 2018

\section{References}

1. Rebecca L, Siegel M, Kimberly D, Miller M, Ahmedin Jemal DP. Cancer statistics, 2017. CA-CANCER J CLIN. 2017;67:7-30

2. van Driel WJ, Koole SN, Sikorska K, Schagen VU, Schreuder H, Hermans R, et al. Hyperthermic intraperitoneal chemotherapy in ovarian Cancer. N Engl J Med. 2018:378:230-40

3. Al RT, Lopes AD, Bristow RE, Bryant A, Elattar A, Chattopadhyay S, et al. Surgical cytoreduction for recurrent epithelial ovarian cancer. Cochrane Database Syst Rev. 2013;2:D8765.

4. Dancey J. Targeted therapies and clinical trials in ovarian cancer. Ann Oncol. 2013;24:x59-63.

5. Sundar S, Neal RD, Kehoe S. Diagnosis of ovarian cancer. BMJ. 2015;351: h4443.

6. Gad Singer RSHK. Patterns of p53 mutations separate ovarian serous borderline tumors and low- and high-grade carcinomas and provide support for a new model of ovarian carcinogenesis. Am J Surg Pathol. 2005; 29:218-24

7. Mantia-Smaldone GM, Edwards RP, Vlad AM. Targeted treatment of recurrent platinum-resistant ovarian cancer: current and emerging therapies. Cancer Manag Res. 2011;3:25-38.
8. Matsuura K, Huang N, Cocce K, Zhang L, Kornbluth S. Downregulation of the proapoptotic pr otein MOAP-1 by the UBR5 ubiquitin ligase and its role in ovarian cancer resistance to cisplatin. Oncogene. 2016;36:1698.

9. Niero EL, Rocha-Sales B, Lauand C, Cortez BA, de Souza MM, RezendeTeixeira $P$, et al. The multiple facets of drug resistance: one history, different approaches. J Exp Clin Cancer Res. 2014;33:37.

10. Agarwal R, Kaye SB. Ovarian cancer: strategies for overcoming resistance to chemotherapy. Nat Rev Cancer. 2003;3:502-16.

11. Lopez-Lazaro M. Distribution and biological activities of the flavonoid luteolin. Mini Rev Med Chem. 2009;9:31-59.

12. Lin $Y$, Shi R, Wang $X$, Shen HM. Luteolin, a flavonoid with potential for cancer prevention and therapy. Curr Cancer Drug Targets. 2008;8:634-46.

13. Horinaka M, Yoshida T, Shiraishi T, Nakata S, Wakada M, Nakanishi R, et al. Luteolin induces apoptosis via death receptor 5 upregulation in human malignant tumor cells. Oncogene. 2005:24:7180-9.

14. Fang J, Zhou Q, Shi XL, Jiang BH. Luteolin inhibits insulin-like growth factor 1 receptor signaling in prostate cancer cells. Carcinogenesis. 2006;28:713-23.

15. Song S, Su Z, Xu H, Niu M, Chen X, Min H, et al. Luteolin selectively kills STAT3 highly activated gastric cancer cells through enhancing the binding of STAT3 to SHP-1. Cell Death Dis. 2017:8:e2612

16. Ong C, Zhou J, Ong C, Shen H. Luteolin induces G1 arrest in human nasopharyngeal carcinoma cells via the Akt-GSK-3 $\beta$-cyclin D1 pathway. Cancer Lett. 2010;298:167-75.

17. Chian SLYW. Luteolin sensitizes two Oxaliplatin-resistant colorectal Cancer cell lines to chemotherapeutic drugs via inhibition of the Nrf2 pathway. Asian Pac J Cancer Prev. 2014;15:2911-6.

18. Tu S, Ho C, Liu M, Huang C, Chang H, Chang C, et al. Luteolin sensitises drug-resistant human breast cancer cells to tamoxifen via the inhibition of cyclin E2 expression. Food Chem. 2013;141:1553-61.

19. Du H, Liu Y, Chen X, Yu X, Hou X, Li H, et al. DT-13 synergistically potentiates the sensitivity of gastric cancer cells to topotecan via cell cycle arrest in vitro and in vivo. Eur J Pharmacol. 2018:818:124-31.

20. Ren Y, Zhou X, Mei M, Yuan XB, Han L, Wang GX, et al. MicroRNA-21 inhibitor sensitizes human glioblastoma cells U251 (PTEN-mutant) and LN229 (PTEN-wild type) to taxol. BMC Cancer. 2010;10:27.

21. ZJ J. About the evaluation of drug combination. Acta Pharmacol Sin. 2004; 25:146-7

22. Baguley BC. Multiple drug resistance mechanisms in Cancer. Mol Biotechnol. 2010;46:308-16.

23. Sarosiek KA, Fraser C, Muthalagu N, Bhola PD, Chang W, McBrayer SK, et al. Developmental regulation of mitochondrial apoptosis by c-Myc governs ageand tissue-specific sensitivity to Cancer therapeutics. Cancer Cell. 2017:31:142-56.

24. Nguyen M, Marcellus RC, Roulston A, Watson M, Serfass L, Murthy MS, et al. Small molecule obatoclax (GX15-070) antagonizes MCL-1 and overcomes MCL-1mediated resistance to apoptosis. Proc Natl Acad Sci U S A. 2007;104:19512-7.

25. Chen P, Hu T, Ma Y, Chen X, Dai L, Lei N, et al. Abstract 2808: Luteolin inhibits cell proliferation and induces cell apoptosis via down-regulation of mitochondrial membrane potential in esophageal carcinoma cells EC1 and KYSE450. Cancer Res. 2015:75:2808.

26. Xavier CPR, Lima CF, Preto A, Seruca R, Fernandes-Ferreira M, Pereira-Wilson C. Luteolin, quercetin and ursolic acid are potent inhibitors of proliferation and inducers of apoptosis in both KRAS and BRAF mutated human colorectal cancer cells. Cancer Lett. 2009:281:162-70.

27. Czabotar PE, Lessene G, Strasser A, Adams JM. Control of apoptosis by the BCL-2 protein family: implications for physiology and therapy. NAT REV MOL CELL BIO. 2014;15:49-63.

28. Inoue-Yamauchi A, Jeng PS, Kim K, Chen H, Han S, Ganesan YT, et al. Targeting the differential addiction to anti-apoptotic BCL-2 family for cancer therapy. Nat Commun. 2017;8:16078.

29. Cheng MCW EHYA. BCL-2, BCL-XL Emily H.-Y. A. Cheng,1 1 sequester BH3 domain-only molecules preventing BAX-and BAK-mediated mitochondrial apoptosis. MOL Cell. 2001;8:705-11.

30. PALMER JE, SANT CASSIA L, IRWIN CJ, MORRIS AG, ROLLASON TP. P53 and bcl-2 assessment in serous ovarian carcinoma. Int J Gynecol Cancer. 2008:18:241-8.

31. Fauvet R, Dufournet C, Poncelet C, Uzan C, Hugol D, Darai E. Expression of pro-apoptotic (p53, p21, bax, bak and fas) and anti-apoptotic (bcl-2 and bcl$x)$ proteins in serous versus mucinous borderline ovarian tumours. J Surg Oncol. 2005:92:337-43.

32. Wang H, Zhang Z, Wei X, Dai R. Small-molecule inhibitor of BCl-2 (TW-37) suppresses growth and enhances cisplatin-induced apoptosis in ovarian cancer cells. J OVARIAN RES. 2015;8:3. 
33. Zheng $\mathrm{CH}$, Zhang $\mathrm{M}$, Chen $\mathrm{H}$, Wang $\mathrm{CQ}$, Zhang $\mathrm{MM}$, Jiang $\mathrm{JH}$, et al. Luteolin from Flos Chrysanthemi and its derivatives: new small molecule Bcl-2 protein inhibitors. Bioorg Med Chem Lett. 2014;24:4672-7.

34. Hudson LG, Zeineldin R, Stack MS. Phenotypic plasticity of neoplastic ovarian epithelium: unique cadherin profiles in tumor progression. CLIN EXP METASTAS. 2008;25:643-55.

35. Joseph E, BRKW DL. Progression and Enhancement of metastatic potential after exposure of tumor cells to chemotherapeutic Agents1. Cancer Res. 2001;61:2857-61.

36. Yang $J M, X u Z, W u H, Z h u H, W u X$, Hait WN. Overexpression of extracellular matrix metalloproteinase inducer in multidrug resistant cancer cells. Mol Cancer Res. 2003;1:420-7.

37. Fu X, Tian J, Zhang L, Chen Y, Hao Q. Involvement of microRNA-93, a new regulator of PTEN/Akt signaling pathway, in regulation of chemotherapeutic drug cisplatin chemosensitivity in ovarian cancer cells. FEBS Lett. 2012;586: 1279-86.

38. Matthew T, Cook YLCB. Luteolin inhibits lung metastasis, cell migration, and viability of triple-negative breast cancer cells. Breast Cancer - Targets and Therapy. 2017;9:9-19.

39. Ke-Hung Tsui LCTF. Upregulation of prostate-derived Ets factor by luteolin causes inhibition of cell proliferation and cell invasion in prostate carcinoma cells. Int J Cancer. 2011;130:2812-23.

Ready to submit your research? Choose BMC and benefit from:

- fast, convenient online submission

- thorough peer review by experienced researchers in your field

- rapid publication on acceptance

- support for research data, including large and complex data types

- gold Open Access which fosters wider collaboration and increased citations

- maximum visibility for your research: over $100 \mathrm{M}$ website views per year

At $\mathrm{BMC}$, research is always in progress.

Learn more biomedcentral.com/submissions 